
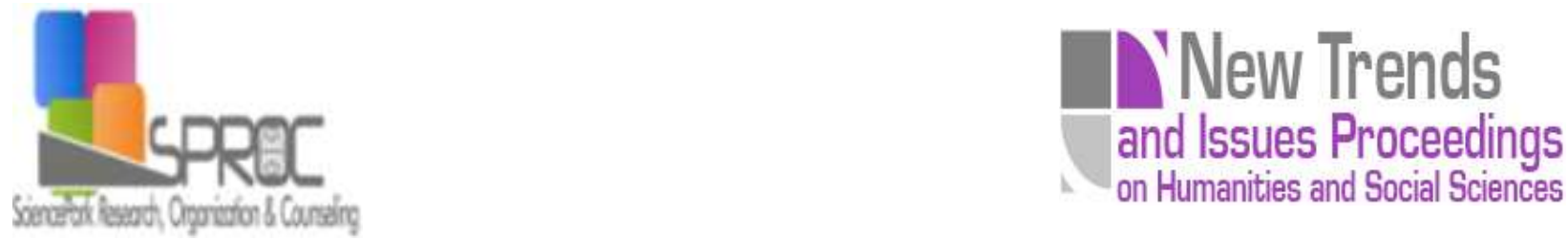

\title{
Apps for Solving Engineering Problems Using Numerical Techniques
}

Marta Graciela Caligaris *

Georgina Beatriz Rodriguez ${ }^{b}$

Lorena Fernanda Laugero

Jose Ernesto Valentini ${ }^{d}$

Suggested Citation:

Abstract

Marta Graciela Caligaris, 
1. Introduction

2. Mathematics in Science context

- 
3. Teaching Numerical Analysis in Engineering context 


$$
\begin{aligned}
& \text { NVP }=\sum_{\mathrm{k}=0}^{\mathrm{n}} \frac{\mathrm{Cf}_{\mathrm{k}}}{(1+\mathrm{i})^{\mathrm{k}}} \\
& 0=\sum_{\mathrm{k}=0}^{\mathrm{n}} \frac{\mathrm{Cf}_{\mathrm{k}}}{(1+\mathrm{IRR})^{\mathrm{k}}}
\end{aligned}
$$

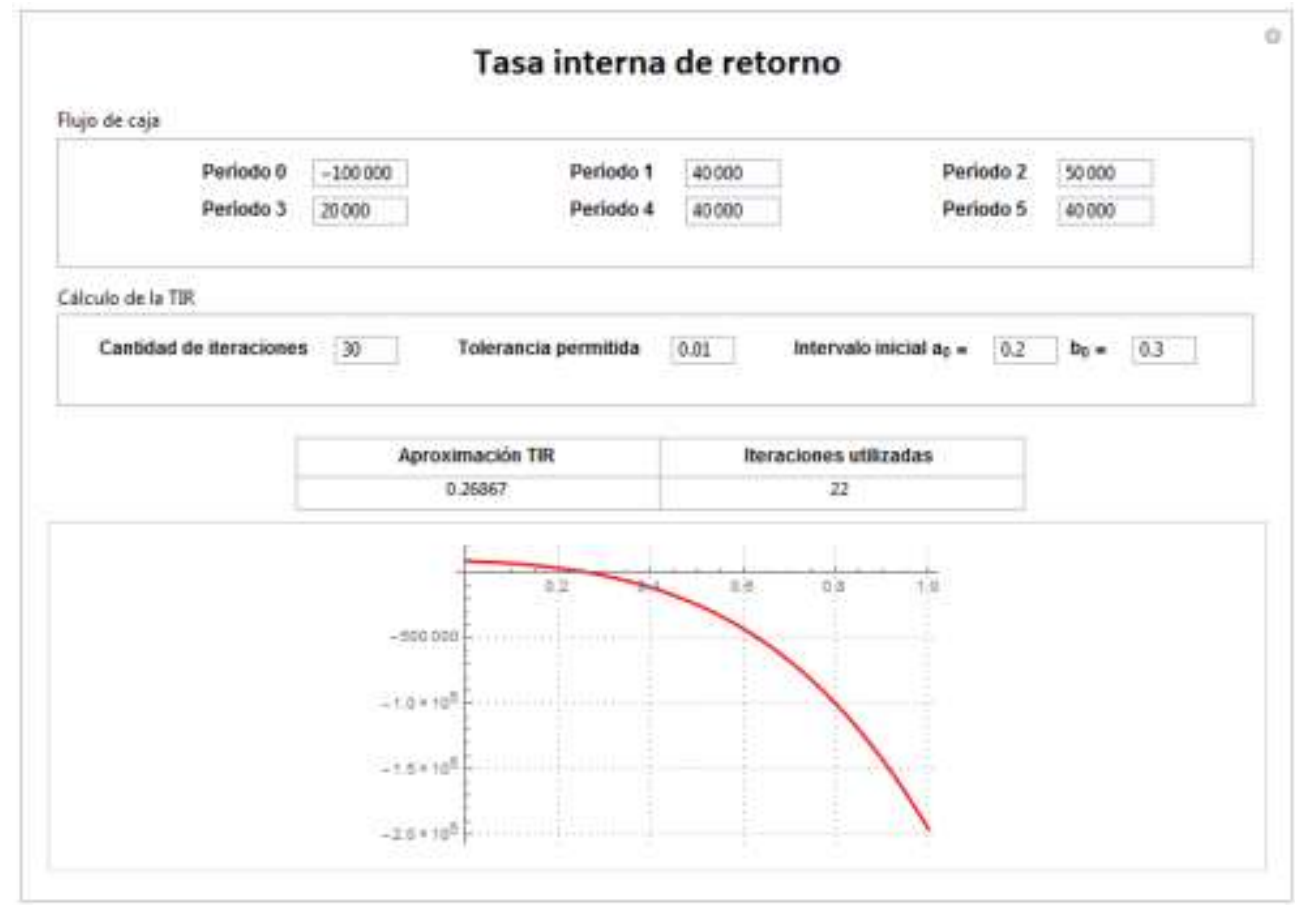

Figure 1. A tool for evaluating the internal rate of return 


\subsection{A tool for analyzing four-bar linkage mechanisms}

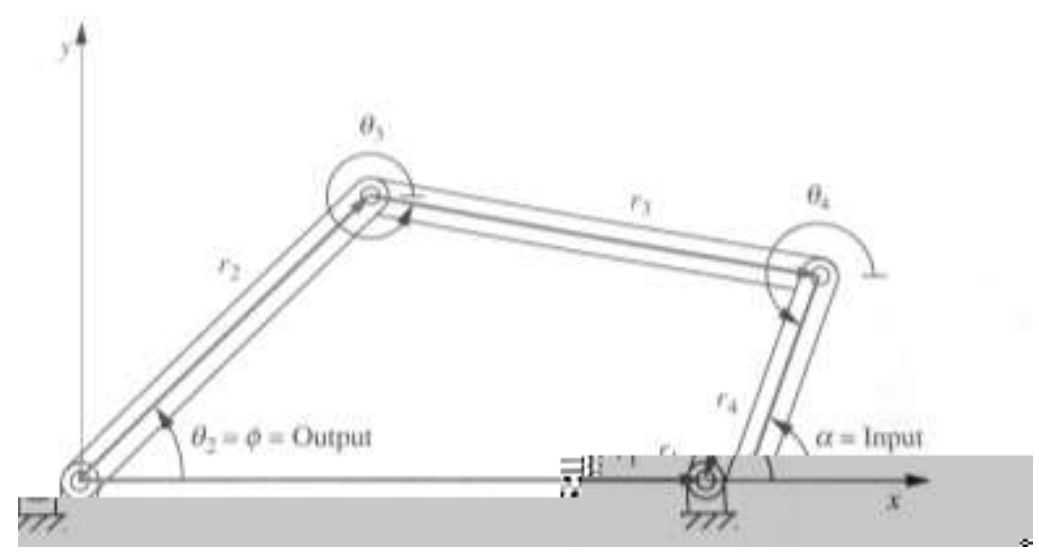

Figure 2. A four-bar linkage mechanism

$$
\begin{gathered}
r_{2} \cos \left(\theta_{2}\right)+r_{3} \cos \left(\theta_{3}\right)+r_{4} \cos \left(\theta_{4}\right)-r_{1}=0 \\
r_{2} \sin \left(\theta_{2}\right)+r_{3} \sin \left(\theta_{3}\right)+r_{4} \sin \left(\theta_{4}\right)=0 \\
\theta \quad \phi \quad \theta=\alpha \quad \pi \\
R_{1} \cos (\alpha)-R_{2} \cos (\phi)+R_{3}-\cos (\alpha-\phi)=0 \\
R_{1}=\frac{r_{1}}{r_{2}}, \quad R_{2}=\frac{r_{1}}{r_{4}} \text { and } R_{3}=\frac{r_{1}^{2}+r_{2}^{2}-r_{3}^{2}+r_{4}^{2}}{2 r_{2} r_{4}} \\
\frac{5}{3} \cos (\alpha)-\frac{5}{2} \cos (\phi)+\frac{11}{6}-\cos (\alpha-\phi)=0 \\
\phi
\end{gathered}
$$

$\alpha$ 


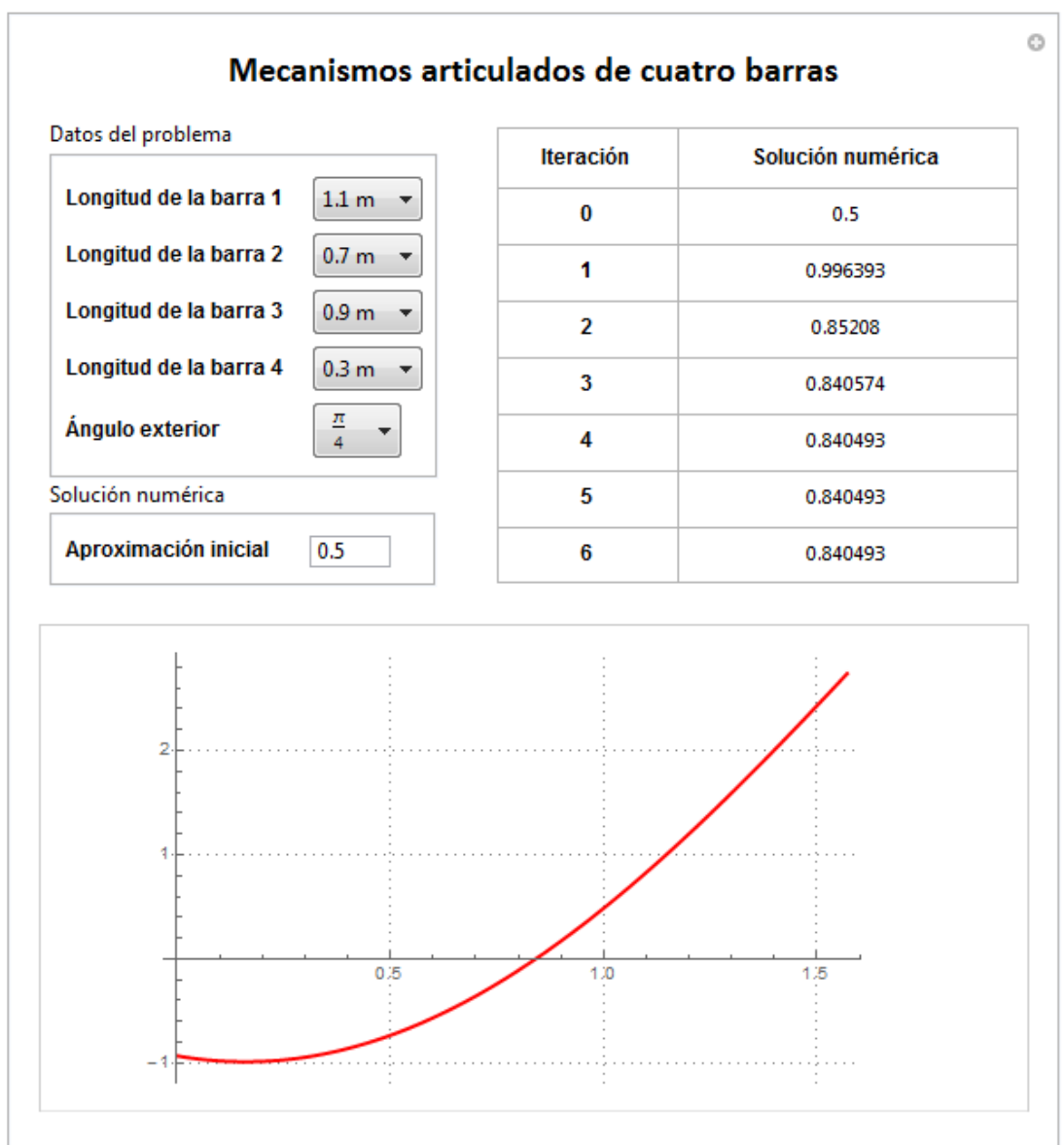

Figure 3. A tool for solving a four-bar linkage mechanism

3.4. A tool for studying real gases 


$$
\left(P+\frac{a}{V^{2}}\right)(V-b)=R T
$$

$$
\mathrm{V}_{0}=\mathrm{b}+\frac{\mathrm{RT}}{\mathrm{P}}
$$

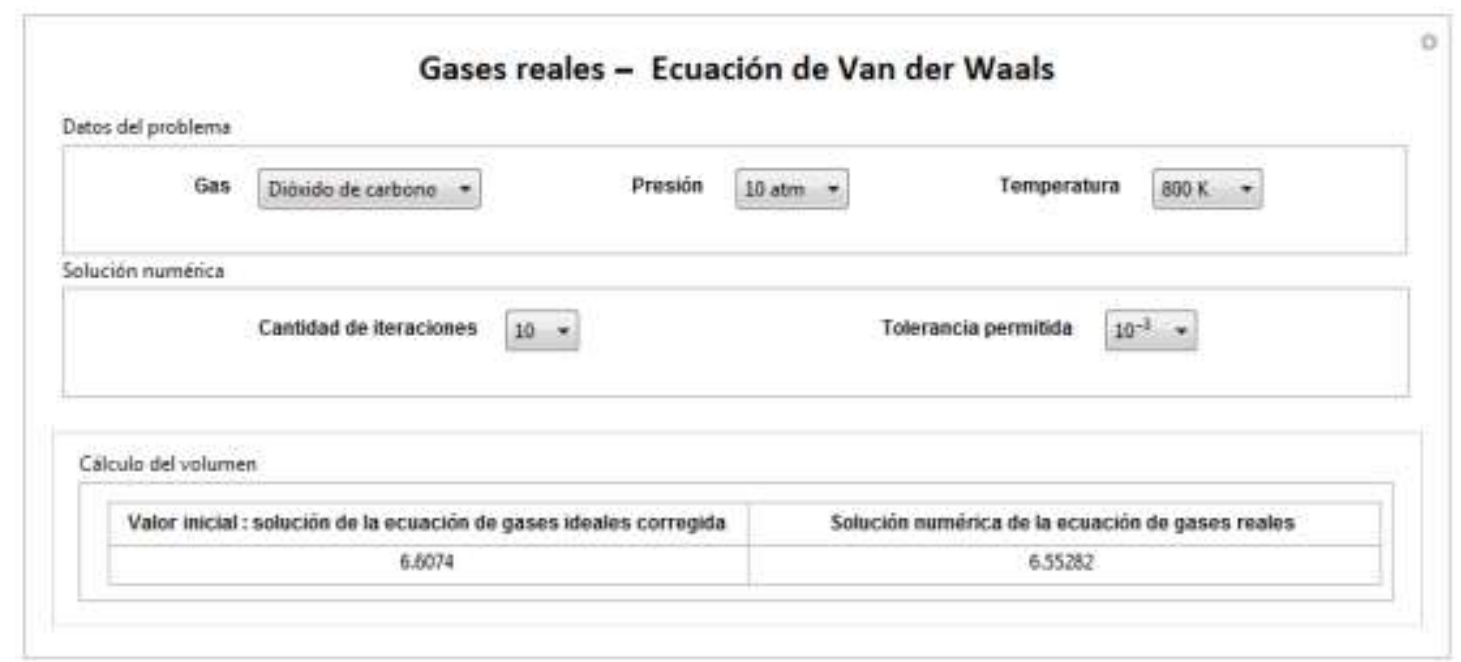

Figure 4. A tool for studying real gases

\section{Conclusion}


eferences 